\title{
Alanyl-tRNA synthetase gene of the extreme acidophilic chemolithoautotrophic Thiobacillus ferrooxidans is highly homologous to alas genes from all living kingdoms but cannot be transcribed from its promoter in Escherichia coli
}

\author{
Nicolas Guiliani, Abderrahmane Bengrine, Françoise Borne, \\ Marc Chippaux and Violaine Bonnefoy
}

Author for correspondence: Violaine Bonnefoy. Tel: +334911641 46. Fax: +33491718914. e-mail: bonnefoy@ibsm.cnrs-mrs.fr

Laboratoire de Chimie Bactérienne, Institut de Biologie Structurale et de Microbiologie, 31 chemin Joseph Aiguier, 13402 Marseille Cedex 20, France
The alas gene of Thiobacillus ferrooxidans has been cloned and sequenced and its expression in Escherichia coli and $T$. ferrooxidans analysed. The same genomic organization to that in E. coli (recA-recX-alas) has been found in $T$. ferrooxidans. The recA and alas genes cannot be transcribed from their own promoters in E. coli. In addition to the well-known homology at the protein level between AlaS proteins from various organisms, a strong homology was found between all the known alas genes from bacteria, archaea and eucarya. Two regions, one of which corresponds to the catalytic core, are particularly well-conserved at the nucleotide sequence level, a possible indication of strong constraints during evolution on these parts of the genes.

Keywords: Thiobacillus ferrooxidans, alanyl-tRNA synthetase, RecX

\section{INTRODUCTION}

Comparative analysis of primordial proteins arisen early in evolution and study of their genes could shed some light on the organization and evolution of the genome in different organisms. Cairns-Smith et al. (1992) have proposed that the origin of life was mineral and it is generally agreed that the Thiobacillus ferrooxidans way of life is one of the most primitive. To grow this bacterium, which is well-adapted to extremely low-pH environments, only requires air, which provides carbon and nitrogen, and ferrous iron or reduced sulfur compounds from pyrite as an energy source (reviewed by Leduc \& Ferroni, 1994). T. ferrooxidans is one of the main micro-organisms involved in bioleaching (Temple \& Colmer, 1951), that is the solubilization of metals from minerals. Because of its unusual growth requirements, and despite its industrial importance, our current knowledge of the physiology, biochemistry and genetics of $T$. ferrooxidans is still very poor. Therefore, when we

Abbreviation: RT-PCR, reverse transcription-PCR.

The EMBL/GenBank accession number for the sequence reported in this paper is $X 95571$. unexpectedly obtained part of the alanyl-tRNA synthetase gene of T. ferrooxidans ATCC 33020, we decided to pursue its study because (i) aminoacyl-tRNA synthetases are key enzymes which ensure fidelity of protein biosynthesis by specifically charging tRNAs with their cognate amino acids, and they are supposed to have co-evolved with tRNAs since the origin of life (Nagel \& Doolittle, 1991; Schimmel et al., 1993); (ii) even though aminoacyl-tRNA synthetases are diverse in subunit composition, polypeptide size and amino acid sequence, synthetases specific for one given amino acid, but from diverse organisms, are more similar to each other than they are to enzymes specific for any other amino acid in the same organism. This supports the idea that these enzymes appeared in evolution before the divergence of the different organism groups; (iii) according to Schimmel (1991), the class-defining conserved domain of the alanyl-tRNA synthetase may reflect the primordial synthetase because this enzyme makes no contact with the tRNA anticodon (Schimmel, 1990). Instead, recognition is concentrated on the amino acid accepter helix and is centred on a single base pair, G3U70 (Schimmel, 1990).

Study of alanyl-tRNA synthetase from $T$. ferrooxidans 
is therefore of evolutionary interest. In this paper, the $T$. ferrooxidans alaS gene has been sequenced and compared to other alanyl-tRNA synthetase genes. Its expression in Escherichia coli and T. ferrooxidans has also been analysed.

\section{METHODS}

Strains, plasmids and growth conditions. T. ferrooxidans ATCC 33020 was obtained from the American Type Culture Collection. Initial screening of the recombinant $T$. ferrooxidans chromosomal library, the propagation of cosmids and complementation analysis of the recA mutant were performed in E. coli HB101 [ $\Delta$ (gpt-proA)62 leuB6 thi-1 lacY1 hsdB20 recA rpsL20 ara-14 galK2 xyl-5 mtl-1 supE44 $m c r B_{\mathrm{B}}$ ]. TG1 [supE hsd $\Delta 5$ thi $\Delta($ lac-proAB $), \mathrm{F}^{\prime}:$ traD 36 proAB ${ }^{+}$lacl $^{\mathrm{q}}$ lacZ $\triangle M 15]$ was used for phagemid propagation. AB4132 (alaS4 thi-1 metC56 lacY1 galK2 $x y l-5$ or $x y l-7$ ara-14 tfr-15 ts $x$-57 supE44) was used for the complementation analysis of alas.

The phagemid pBluescript (Stratagene) was used for preparation of clones for sequencing.

E. coli growth conditions were as described in Miller (1992). For analysing the $\operatorname{rec} A$ phenotype, methyl methanesulfonate (MMS) was used at $0.01 \%(\mathrm{w} / \mathrm{v})$. T. ferrooxidans growth conditions were as published previously (Guiliani et al., 1993).

General DNA techniques. General DNA techniques were performed according to Ausubel et al. (1991). Ultrapure cosmid DNA was prepared using Qiagen plasmid kits. Digestions with restriction endonucleases were carried out as recommended by the manufacturer. DNA fragment bluntending and ligation were performed with the DNA blunting kit from Amersham. Preparation of competent E. coli and transformation were performed according to Chun et al. (1989).

Colony and Southern hybridization with degenerate oligonucleotides. Two oligonucleotides were designed from the amino acid sequences KDGKFGY and FDITKK (amino acids 115-121 and 87-93, respectively) present in the three rusticyanins characterized from three different strains of $T$. ferrooxidans. The sequence of the first oligonucleotide, Rus115, was 5'-TARCCRAAYTTRCCRTCYTT-3' (64-fold degeneracy), the third nucleotide of each codon being changed according to the codon usage of $T$. ferrooxidans (Rawlings et al., 1991). The second oligonucleotide, Rus87, was 5'CCYTTYTTNGTDATRTCRAA-3' (192-fold degeneracy). Rus115 and Rus87 were purchased from Appligene. Rus115 was labelled with $\left[\gamma_{-}{ }^{32} \mathrm{P}\right]$ ATP (Ausubel et al., 1991) and used for colony hybridization under stringent conditions (Ausubel et al., 1991) of E. coli HB101 colonies transfected with a $T$. ferrooxidans ATCC 33020 (pHC79) cosmid library kindly provided by D. E. Rawlings, University of Cape Town, South Africa.

Southern hybridization experiments were performed on cosmid DNA cleaved with different restriction enzymes. After electrophoresis, the DNA was denatured and transferred to a positively charged nylon membrane (Hybond-N + from Amersham) by the semi-dry capillary method (Sambrook et al., 1989). Prehybridization and hybridization were carried out under stringent conditions. Non-radioactive oligonucleotide labelling of Rus 115 and detection were performed with the ECL 3'-oligolabelling system and ECL detection reagents purchased from Amersham.
DNA sequencing. Both strands of the $1.9 \mathrm{~kb} P s t \mathrm{I}$ and of the $3.5 \mathrm{~kb}$ HindIII-KpnI DNA fragments were sequenced after convenient subcloning of overlapping fragments had been performed, and nested deletions generated by combined ExoIII/ExoVII digestions as previously described (Blasco et al., 1989). When necessary, DNA fragments were amplified by PCR between two convergent oligonucleotides designed from the known nucleotide sequence, and were either directly sequenced according to Salles et al. (1992), or subcloned in pBluescript KS or SK $(+)$ or $(-)$ and sequenced. The dideoxy chain-termination method was used to sequence DNA using $\left[{ }^{35} \mathrm{~S}\right] \mathrm{dATP} \alpha \mathrm{S}$ and the T7 Sequencing kit (Pharmacia).

PCR reactions were performed with Taq polymerase according to the manufacturer's recommendations in a Minicycler (MG research). All synthetic oligonucleotides for PCR and sequencing were purchased from Genset.

The DNA sequences were compiled, analysed and compared with the EMBL database sequences with the UWGCG package (Devereux et al., 1984), CLUSTAL, BLAST (Altschul et al., 1990) or BioScan programs through the WWW Nestcape facilities. RNA secondary structures were analysed with the RNAFOLD and SQUIGGLES programs in the UWGCG package (Devereux et al., 1984).

RNA preparation. $T$. ferrooxidans total RNA was prepared from a $500 \mathrm{ml}$ culture grown on $\mathrm{FeSO}_{4}$ medium by a slightly modified hot phenol method (Aiba et al., 1981). After washing the cells with $9 \mathrm{~K}$ basal salts, the pellet was resuspended in $500 \mu \mathrm{l} 0.02 \mathrm{M}$ sodium acetate (pH 5.5), $0.5 \%$ SDS, $1 \mathrm{mM}$ EDTA. The lysed cells were extracted twice at $60^{\circ} \mathrm{C}$ with phenol equilibrated with $0.02 \mathrm{M}$ sodium acetate $(\mathrm{pH} 5.5)$, $0.5 \%$ SDS, 1 mM EDTA. RNA was precipitated with ethanol and resuspended in $200 \mu \mathrm{l} 10 \mathrm{mM}$ Tris (pH 8). DNA-free RNA was then obtained with the High Pure RNA isolation kit from Boehringer, omitting the lysozyme step.

Reverse transcription-PCR (RT-PCR). RT-PCR was performed with the Promega Access system. One microgram of total RNA from $T$. ferrooxidans was denatured at $94^{\circ} \mathrm{C}$ for $2 \mathrm{~min}$ in the presence of both oligonucleotides. Immediately, reverse transcription and PCR amplification were carried out according to Promega recommendations with the following program: $48^{\circ}$ for $1 \mathrm{~h} ; 94^{\circ} \mathrm{C}$ for $5 \mathrm{~min} ; 30,45$ or 60 cycles of $45 \mathrm{~s}$ at $94^{\circ} \mathrm{C}, 30 \mathrm{~s}$ at $62^{\circ} \mathrm{C}, 30 \mathrm{~s}$ at $72{ }^{\circ} \mathrm{C} ; 72^{\circ} \mathrm{C}$ for $3 \mathrm{~min}$. Oligonucleotides used were: alaS21, 5'-CGTTGTGTTTGCCACCCGC-3'; alaS33, 5'-TCGTGCCCTCCAGCCCCC3'; RA3, 5'-GCCGAAGAGGTGGCAGAGC-3'; RA5, 5'GCCGGGCATAATCTCTGGCG-3'; RX1， 5'-GATTGACAGCGGGTGAGGGG-3'.

For each RT-PCR experiment, three controls were performed: one without template as a negative control to detect any contamination, one with genomic DNA as a control for PCR amplification, one with RNA but without reverse transcriptase to check that there were no DNA traces in the RNA preparation. In each case, PCR was performed for 30 and 45 cycles, and when no amplification product was detected, for 60 cycles.

\section{RESULTS}

\section{Molecular cloning of the $T$. ferrooxidans alaS region}

Two degenerate oligonucleotides, Rus115 and Rus87, designed on the basis of two highly conserved segments in rusticyanins were used to screen a $T$. ferro- 
oxidans(pHC79) cosmid library. Out of 1100 colonies tested, 19 gave a positive signal with Rus115 under stringent conditions. They also responded positively with the second oligonucleotide, Rus 87 . The cosmid DNA was prepared from each clone, digested with EcoRI and probed with Rus115. All contained only one fragment which responded positively, the size of the fragment ranging from 8 to $18 \mathrm{~kb}$ (data not shown). When digested with other restriction enzymes, 15 cosmids were found to contain a single $1.9 \mathrm{~kb}$ Pst $\mathrm{I}$ fragment hybridizing with Rus115, the other four containing a $2 \mathrm{~kb}$ Pstl fragment (data not shown).

Therefore, the $1.9 \mathrm{~kb}$ PstI DNA fragment of one of these cosmids, pNG4, was cloned in pBluescript $\mathrm{SK}(+)$ and sequenced. No ORF corresponding to the rusticyanin protein could be found. On the contrary, comparison of the nucleotide sequence with the EMBL database sequences, revealed the $3^{\prime}$ end of the $\operatorname{rec} A$ gene, previously sequenced by Ramesar et al. (1988, 1989), and the $5^{\prime}$ end of a previously uncharacterized gene showing a high degree of similarity with the nucleotide sequence of the alaS genes of E. coli (67.5\% identity) (Putney et al., 1981), Sinorhizobium (Rhizobium) meliloti $(68 \%)$ and $R$. leguminosarum biovar viciae $(68 \%)$ (Selbitschka et al., 1991). The AlaS protein is an alanyl-tRNA synthetase which catalyses the specific attachment of alanine to its cognate tRNA. Since nearly all the 19 different cosmids contained the same $1.9 \mathrm{~kb}$ PstI fragment, we can exclude joining of two different non-contiguous fragments during library construction. This was confirmed by PCR amplification of $T$. ferrooxidans DNA with oligonucleotides corresponding to recA and alaS (see Fig. 4).

\section{Expression of the recA and alaS genes in $E$. coli}

To confirm that we had indeed cloned a T. ferrooxidans alaS gene, complementation studies were carried out using two different mutants of $E$. coli: a recA strain and an ala $S^{\text {ts }}$ strain. The former is sensitive to UV irradiation and to MMS treatment while the latter, which carries an allele encoding a thermosensitive $\mathrm{AlaS}$ protein, can grow at $30^{\circ} \mathrm{C}$ but fails to develop at $42^{\circ} \mathrm{C}$. Surprisingly, while nearly all of the cosmids contained the same Pst fragment, only cosmid pNG12 could restore (i) resistance of the recA mutant to UV or MMS and (ii) growth of the E. coli ala $S^{\text {ts }}$ mutant at $42{ }^{\circ} \mathrm{C}$. This result showed that a $T$. ferrooxidans alaS gene is present on pNG12 and indicated that it can be transcribed and translated into a functional AlaS protein in E. coli.

The restriction analysis of the three cosmids, pNG3, 4 and 12 , indicated that they all carried both recA and alaS genes (Fig. 1) even though only pNG12 complemented the E. coli recA and alaS strains. By comparison of the restriction maps of pNG4 and of the recA region (Ramesar et al., 1989), and accounting for the size of the E. coli AlaS protein, it was deduced that the $r e c A$ and alaS genes should be located on a $5 \mathrm{~kb} K p n \mathrm{I}$ fragment. When this fragment was cloned from pNG4 into pUC19
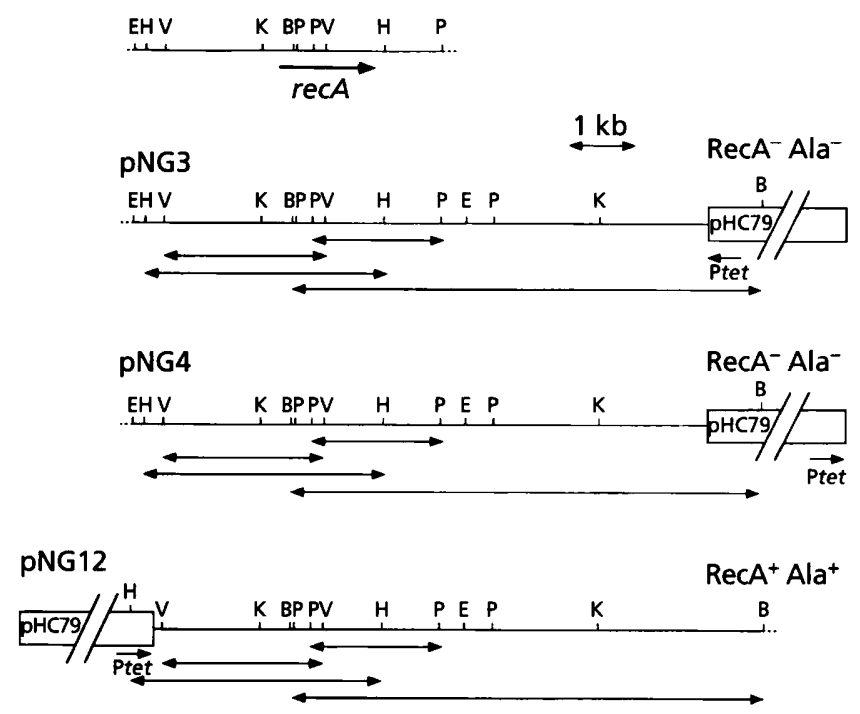

Fig. 1. Restriction maps of the recA region (Ramesar et al., 1988, 1989), and pNG3, pNG4 and pNG12. The phenotype conferred by these cosmids upon recA and alaS mutants of $E$. coli is indicated on the top right. The limits of the recA gene have been deduced from the recA sequence (Ramesar et al., 1989). Boxes represent pHC79. The direction of transcription from the tet promoter (Ptet) is shown below pHC79. B, E, H, K, $P$ and $V$ represent $B g / l l, E c o R l, H i n d I I I, K p n l, P s t l$ and EcoRV restriction sites. Arrows under pNG3, 4 and 12 indicate the restriction fragments hybridizing with the Rus115 oligonucleotide.

to give $\mathrm{pNG} 22$, the $T$. ferrooxidans rec $A$ gene restored UV and MMS resistance to an E. coli recA mutant, but only partial complementation of the E. coli ala $S^{\text {ts }}$ mutant was observed. Ramesar et al. (1989) reported that even when preceded by the upstream $2 \cdot 2 \mathrm{~kb}$, the expression of the $T$. ferrooxidans recA gene in E. coli could only be achieved from a vector-borne promoter. On cosmid pNG12, $2 \mathrm{~kb}$ of the recA upstream region separated the gene from the Ptet promoter carried by the cosmid vector, while $0.5 \mathrm{~kb}$ of the same region is present between the gene and the Plac promoter on plasmid pNG22. All these results suggest that the recA and alaS promoters either are located more than $2 \cdot 2 \mathrm{~kb}$ upstream from $\operatorname{rec} A$, or are not recognized by the $E$. coli RNA polymerase.

Among the 19 cosmids analysed, one would expect that some cosmids would have, upstream from recA gene, a region larger than $2 \cdot 2 \mathrm{~kb}$ likely to carry this promoter. Indeed, the two cosmids, pNG3 and 4, have been shown by restriction mapping to carry more than $25 \mathrm{~kb}$ upstream from recA (Fig. 1). In pNG4, the genes are in the same orientation as the vector-borne promoter Ptet, while in pNG3, they are in the opposite orientation (Fig. 1). Internal deletions of pNG4 were generated by partial EcoRV digestion and recircularization to place these genes at $1.3 \mathrm{~kb}$ from Ptet (Fig. 1). As expected, complementation of $E$. coli recA and alaS mutants was observed, indicating that the genes were functional in 


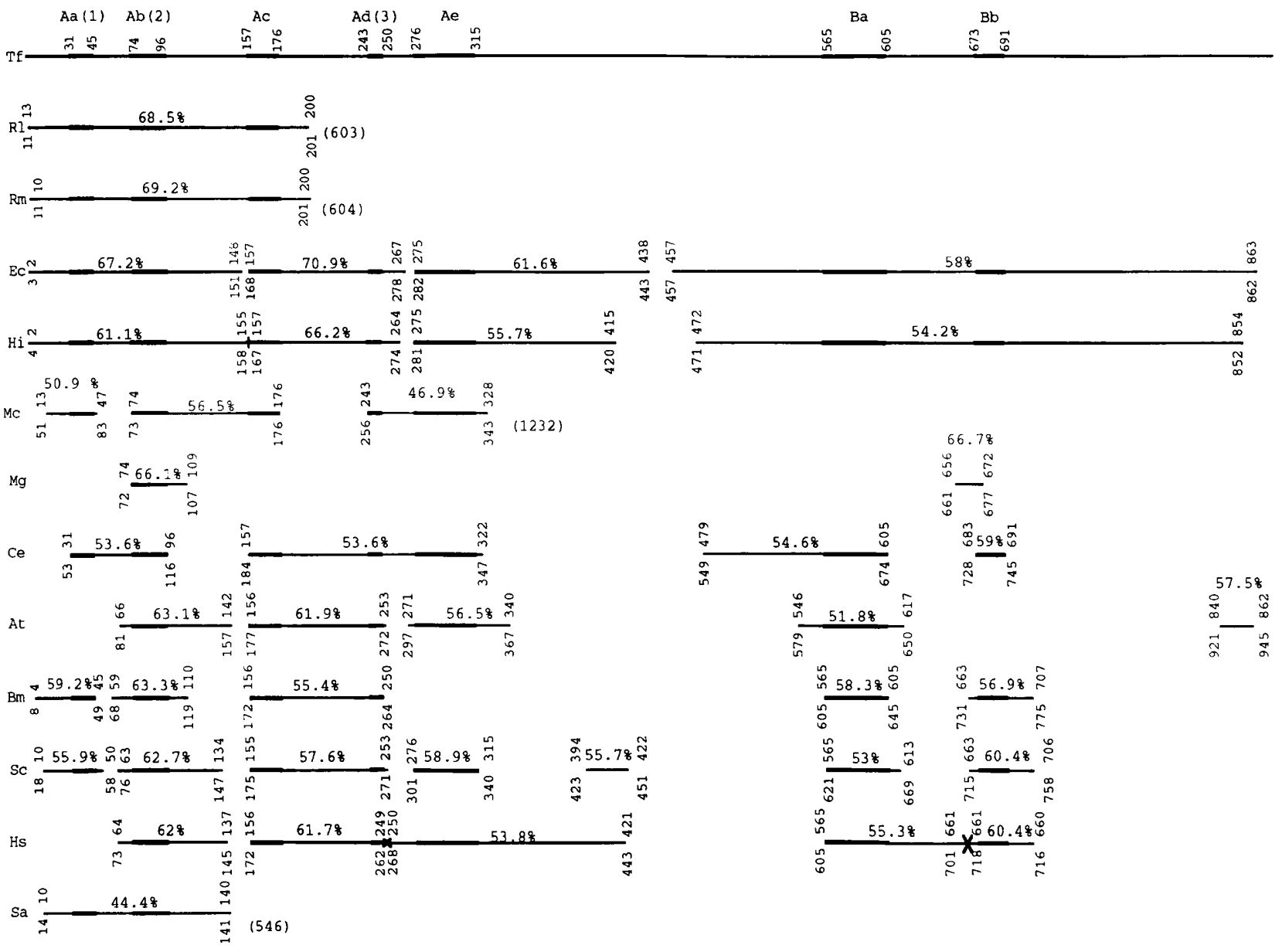

Fig. 2. Schematic representation of alaS genes from $T$. ferrooxidans (Tf), R. leguminosarum (RI), Sin. meliloti (Rm), E. coli (EC), Haem. influenzae (Hi), M. capricolum (Mc), M. genitalium (Mg), C. elegans (Ce), A. thaliana (At), B. mori (Bm), S. cerevisiae (Sc), H. sapiens (Hs) and Sulfolobus acidocaldarius (Sa). Vertical numbers above the line represent positions in the $T$. ferrooxidans AlaS amino acid sequence. Vertical numbers below the line correspond to the position in the AlaS protein of the organism indicated. Where alaS has been partly sequenced, the size of the determined sequence is shown in parentheses. Horizontal numbers represent the percentage identity between regions of the alaS genes from $T$. ferrooxidans and from the organism indicated. The highly conserved regions are shown in bold lines and are noted above the $T$. ferrooxidans alas gene with the class-defining motifs indicated in parentheses.

cosmid pNG4 but were not transcribed. All these results strongly suggest that the $\operatorname{rec} A$ and alaS promoters are not recognized by the E. coli RNA polymerase.

\section{Analysis of the T. ferrooxidans alaS gene}

The $3^{\prime}$ end of alaS is likely located on the $3 \cdot 2 \mathrm{~kb}$ HindIII-KpnI DNA fragment which overlaps the $1.9 \mathrm{~kb}$ Pst I fragment already sequenced. This fragment was blunt-ended with T4 polymerase and cloned into the SmaI site of pBluescript $\mathrm{SK}(-)$, and the nucleotide sequence determined.

A large ORF of $2631 \mathrm{bp}$, positions 672-3302, encoding a putative 877 amino acid polypeptide is present on the same strand as recA. This $95.5 \mathrm{kD}$ a protein shares a high degree of sequence identity with the (partial) alanyltRNA synthetase not only from E. coli $(57 \cdot 4 \%)$ (Putney et al., 1981), Rhizobium leguminosarum (65.5\%) (Selbitschka et al., 1991), Sin. meliloti (66.2\%) (Selbitschka et al., 1991), Haemophilus influenzae $(53.8 \%)$ (Fleischmann et al., 1995) but also from organisms as distantly related as Mycoplasma capricolum $(39.9 \%)$ (P. Bork and others, unpublished results; P. Gillevet and others, unpublished results), Mycoplasma genitalium (33.1\%) (Fraser et al., 1995), Sulfolobus acidocaldarius (39.2\%) (Ramirez et al., 1994), Arabidopsis thaliana $(37.9 \%)$ (H. Mireau and others, unpublished results), Saccharomyces cerevisiae (39.5\%) (Ripmaster et al., 1995), Bombyx mori (36.6\%) (Chang \& Dignam, 1990), Caenorhabditis elegans $(33.5 \%$ ) (Wilson et al., 1994) and Homo sapiens $(38.7 \%$ ) (Shiba et al., 1995). The identity is not restricted to those regions including the residues shown to be important for enzyme activity in E. coli (see below), but occurs along the full length of the proteins. Some similarity is also 
found at the nucleotide sequence level (Fig. 2 and Discussion).

As with other alanyl-tRNA synthetases, the T. ferrooxidans enzyme, TfAlaS, contains the conserved class II motifs, which are localized in the amino terminal half of the primary structure (reviewed by Schimmel, 1990; Eriani et al., 1990; Ribas de Pouplana et al., 1993; Lu \& Hill, 1994; Davis et al., 1994). In each motif, the invariant residue is present as well as several semiinvariant residues of the strongly conserved core. In addition to the class-II-defining motifs, TfAlaS contains the zinc-binding 'cysteine-histidine box' which was shown to be important for tRNA recognition in EcAlaS, the E. coli enzyme (Miller et al., 1991; Miller \& Schimmel, 1992; Wu et al., 1994). Furthermore, the residues important for the catalytic activity of EcAlaS, those required for tRNA recognition (G174, A410), adenylate transfer to the $3^{\prime}$ end of tRNA ${ }^{\text {ala }}$ (D235) and the cognate tRNA aminoacylation (K74, C665, G674, G677) are also present in TfAlaS (Schimmel, 1990; Miller et al., 1991; Filley \& Hill, 1993; Wu et al., 1994; Shi et al., 1994). Note that residues C665, G674 and G677 are not located in the catalytic core of the enzyme but in its 'dispensable' part (Schimmel, 1990; see Discussion).

The overall $\mathrm{G}+\mathrm{C}$ content of the $T$. ferrooxidans alaS $(62.3 \mathrm{~mol} \%)$ gene does not differ significantly from other T. ferrooxidans ATCC 33020 genes (59 mol \%) and the codon usage is typical for ATCC 33020 . The $\mathrm{G}+\mathrm{C}$ content in the codon third position is $71.7 \mathrm{~mol} \%$ in agreement with other $T$. ferrooxidans genes ( $74.3 \mathrm{~mol} \%$ ). A possible ribosome-binding site reading AcGGAaG, at positions $661-667$, is present 4 bp upstream from the alaS putative translational initiation codon but no obvious $\sigma^{70}$ promoter consensus sequence is apparent in the $400 \mathrm{bp}$ region upstream from the alaS ORF. In E. coli, a palindromic sequence involved in the autogenous repression of the gene is located upstream from the initiation codon of the alaS gene (Putney $\&$ Schimmel, 1981). No such sequence can be found upstream from the $T$. ferrooxidans alaS. However, this region contains several indirect repeats which are potentially capable of forming stem-loop structures. Finally, no characteristic rho-independent transcription termination site is present at the $3^{\prime}$ end of alaS, but three pairs of complementary inverted repeats centred at position $3330.5\left(\Delta G=-23.5 \mathrm{kcal} \mathrm{mol}^{-1} /-98.3 \mathrm{~kJ}\right.$ $\left.\mathrm{mol}^{-1}\right), 3361\left(\Delta G=-17.8 \mathrm{kcal} \mathrm{mol}^{-1} /-74.5 \mathrm{~kJ} \mathrm{~mol}^{-1}\right)$ and $3365 \cdot 5\left(\Delta G=-7 \mathrm{kcal} \mathrm{mol}^{-1} /-29 \cdot 2 \mathrm{~kJ} \mathrm{~mol}^{-1}\right)$ lie downstream of the TAG termination codon and could be a rho-dependent transcription terminator.

\section{Analysis of the $T$. ferrooxidans recX gene}

Downstream of the recA gene, De Mot et al. (1994) reported the existence of a putative regulatory gene, recX, conserved in some Gram-negative and -positive bacteria. Using the $T$. ferrooxidans recA sequence determined by Ramesar et al. (1989), De Mot et al.
(1994) found the $5^{\prime}$ end of an ORF which overlaps the recA gene and which encodes a putative polypeptide presenting some homology with RecX.

When determining the sequence downstream of $\operatorname{rec} A$, we corrected the sequence determined by Ramesar et al. (1989); therefore, we have re-examined the potential ORFs in this region. Two potential coding regions, ORF1 and ORF2 are located between recA and alaS at position 211-609 and 330-599, respectively. None corresponds to that proposed by De Mot et al. (1994) deduced from the Ramesar et al. (1989) nucleotide sequence. Analysis of the codon usage and $\mathrm{G}+\mathrm{C}$ content in the codon third position of these two ORFs indicated that both could correspond to typical T. ferrooxidans genes. A search for homologous polypeptides in the protein databases, gave no positive match for the putative polypeptide encoded by ORF1, but revealed a significant similarity between the polypeptide encoded by ORF2 and the Pseudomonas aeruginosa (44.3\% identity) (Sano, 1993) and Pseudomonas fluorescens (37.9\%) (De Mot et al., 1994) RecX proteins and the E. coli OraA protein (35\%) (Zaitsev et al., 1994). Realignment of (partial) RecX sequences from different Gram-negative and -positive bacteria (Azotobacter vinelandii, Legionella pneumophila, Methylomonas clara, Mycobacterium leprae, Pseudomonas putida and Yersinia pestis) with the putative protein corresponding to $T$. ferrooxidans ORF2 also shows some significant similarities. Furthermore, the putative ORF2-encoded polypeptide is quite basic with a high proportion of arginine residues and has a calculated pI of 11.36 , features previously noticed for RecX proteins. All of these data suggest that ORF2 is the recX homologue of $T$. ferrooxidans.

\section{Expression of recA, recX and alaS in T. ferrooxidans}

To determine if the alaS gene is transcribed as a single transcription unit or is part of a larger transcription unit including the recA and $r e c \mathrm{X}$ genes, we have investigated its expression in T. ferrooxidans. Total RNA was isolated from $T$. ferrooxidans cells grown on ferrous iron or sulfur medium, and the alaS specific mRNAs were analysed by Northern blotting with different nonradioactive DNA or RNA probes labelled with DIGdUTP or DIG-UTP, respectively. In all cases, only two bands corresponding to ribosomal RNA were detected (data not shown). A similar result was obtained with the only other $T$. ferrooxidans aminoacyl-tRNA synthetase gene characterized, tyr Z, encoding tyrosyl-tRNA synthetase (O. Salazar, J. Salazar, E. Jedlicki \& O. Orellana, unpublished results). This could suggest that the alaS gene is expressed so weakly that its transcript cannot be detected.

To determine whether the alaS gene is transcribed in $T$. ferrooxidans, RT-PCR was used with oligonucleotides alaS21 and alaS33 that hybridize at the beginning of the alaS coding region. As can be seen in Fig. 3(a), an amplification product of the expected size was obtained 
$\operatorname{rec} A$

$\operatorname{rec} X$

alas

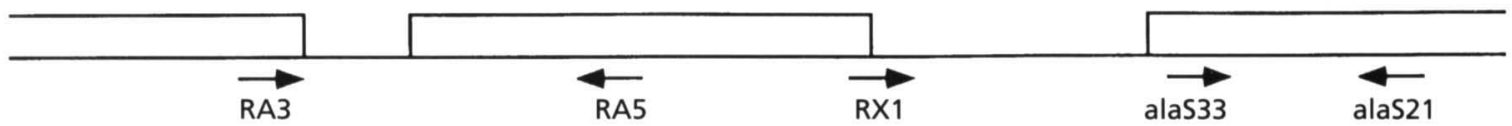

(a) alaS33-alaS21

(b) RA3-alaS21

(c) RX1-alaS21
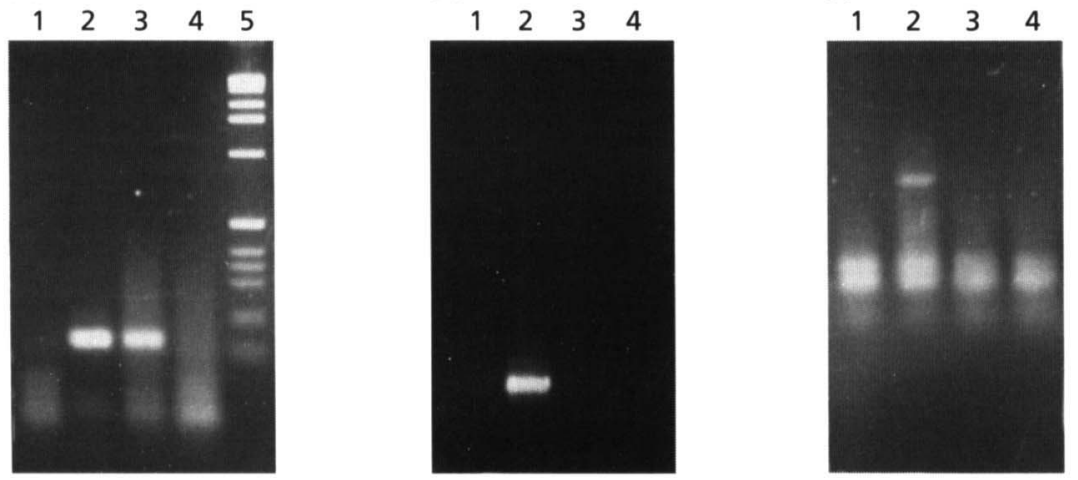

(d) RA3-RA5

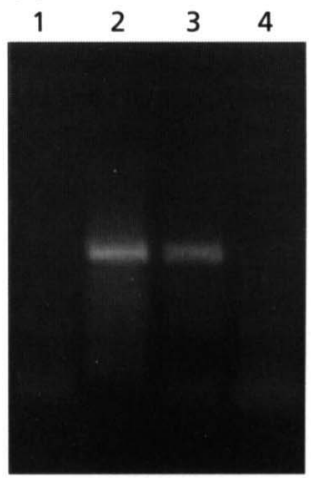

Fig. 3. Analysis of alaS and recX transcription in $T$. ferrooxidans ATCC 33020 by RT-PCR. alas and recX mRNA were detected by reverse transcription from $1 \mu \mathrm{g} \mathrm{T}$. ferrooxidans total RNA and PCR amplification with the following oligonucleotides: (a) alaS33 and alaS21 (45 amplification cycles; $3 \%$ agarose gel); (b) RA3 and alaS21 (45 cycles; $1.5 \%$ agarose); (c) RX1 and alaS21 (60 cycles; $3 \%$ agarose); (d) RA3 and RA5 (45 cycles; $2 \%$ agarose). Locations of the different oligonucleotides relative to the recA, recX and alaS ORFs are shown. Lanes: 1, no template; 2 , chromosomal DNA from ATCC 33020 strain as template; 3, total RNA from ATCC 33020 strain as template; 4, total RNA from ATCC 33020 strain as template but without reverse transcriptase; 5, DNA molecular mass markers (Boehringer).

showing unambiguously that the alaS gene is expressed in T. ferrooxidans.

In E. coli, expression of the alaS and $\operatorname{rec} A$ genes, as judged by complementation of $r e c A$ and $a l a S^{\text {ts }}$ mutants, can only be detected when the genes are expressed from a vector-borne promoter. To determine whether $\operatorname{rec} A$, $r e c X$ and alaS are in a single transcription unit, we have looked for transcripts extending from $\operatorname{rec} A$, or $\operatorname{recX}$, to alaS in T. ferrooxidans by RT-PCR. No amplification product could be detected even after 60 cycles of amplification between the alaS21 and RA3 or RX1 primers located at the beginning of alaS coding region and at the end of the recA and recX ORFs, respectively (Fig. 3b, c). The absence of transcripts extending from the end of the recX coding region to the alaS gene indicates that the $T$. ferrooxidans alaS gene is transcribed independently from $r e c X$, and therefore from $r e c A$, and that the alaS transcriptional start site is located in the recX-alaS intergenic region.

The existence of the recX gene has been deduced from comparisons of recA downstream regions from various micro-organisms (De Mot et al., 1994). Furthermore, it has been shown that the $r e c A$ gene from some of these bacteria can be cloned in a $r e c A$ mutant of $E$. coli only if $r e c X$ is also present on the insert (De Mot et al., 1994). However, until now, there has been no proof that recX is transcribed. To address this question, RT-PCR was performed with the oligonucleotides RA3 and RA5 hybridizing to the end of the $\operatorname{rec} A$ coding region and within the recX ORF, respectively. As shown in Fig. $3(\mathrm{~d})$, an amplification product of the expected size was obtained, indicating that $\operatorname{rec} X$ is transcribed with $r e c A$ in $T$. ferrooxidans.

\section{DISCUSSION}

While trying to clone the rus gene from $T$. ferrooxidans, we also inadvertently cloned its alaS gene. The hybridization experiments were repeated with the Rus115 probe after digestion of three cosmid DNAs (pNG3, 4 and 12) with various restriction enzymes (data not shown), and the Rus115 probe was deduced to hybridize with a $0.18 \mathrm{~kb}$ Pst I-HindIII fragment internal to the PstI-Pst I fragment described above (Fig. 1). In fact, when the Rus115 oligonucleotide sequences were compared to that of this fragment, some of them were found to be partially complementary. As all experiments had been performed under stringent conditions, this result is clearly due to the degeneracy of the oligonucleotides used when screening the $T$. ferrooxidans genomic library.

The identification of the $T$. ferrooxidans cloned gene as encoding an alanyl-tRNA synthetase was unambiguously confirmed by the genetic complementation study which indicated that the $T$. ferrooxidans AlaS (TfAlaS) can substitute for the E. coli AlaS (EcAlaS). In addition, the primary structure of TfAlaS deduced from the nucleotide sequence is similar to that of all known alanyl-tRNA synthetases. This is not surprising since tRNA ${ }^{\text {ala }}$ are very well conserved, in particular the $T$. ferrooxidans tRNA ${ }^{\text {ala }}$ has a high degree of similarity to those from E. coli $(82.9 \%)$ and Bacillus subtilis $(84.2 \%)$ (Venegas et al., 1988). Particular attention has been paid to the region encompassing residues $699-808$ predicted 

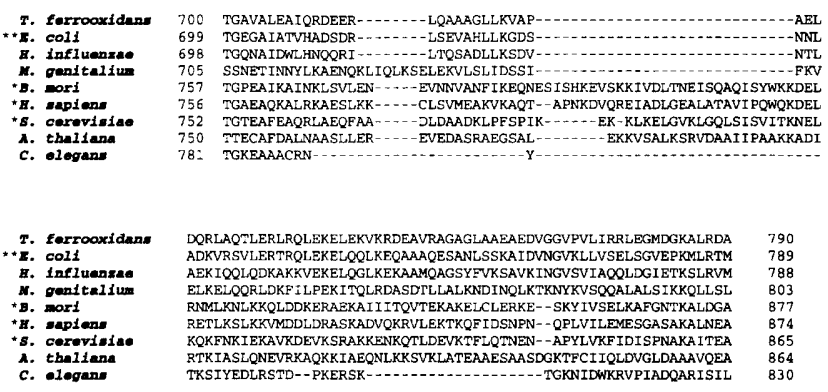

Fig. 4. CLUSTAL alignment of the putative oligomerization domain of the different alanyl-tRNA synthetases known. Gaps are indicated by dashes. The position of the amino acids in the Alas enzymes are indicated. AlaS known to be monomeric and multimeric are denoted respectively by '*' and ' $*$ '.

to be the oligomerization domain of EcAlaS (Jasin et al., 1983). As can be seen in Fig. 4, two main subgroups can be distinguished by the presence or the absence of a segment of about 30 amino acids. Interestingly, EcAlaS, which is tetrameric, does not belong to the group including $S$. cerevisiae, B. mori and H. sapiens AlaS which are monomeric. This could suggest that the first group, including E. coli, Haem. influenzae, T. ferrooxidans and C. elegans AlaS, corresponds to oligomeric synthetases, while the second corresponds to monomeric synthetases.

While the nucleotide sequence is well-conserved along the full length of the alaS coding regions of $T$. ferrooxidans and E. coli, the situation differs between the alaS gene of $T$. ferrooxidans and the alaS genes of eukaryotes such as $S$. cerevisiae, A. thaliana, C. elegans, $B$. mori or $H$. sapiens. Seven discrete regions, $\mathrm{Aa}, \mathrm{Ab}$, $\mathrm{Ac}, \mathrm{Ad}, \mathrm{Ae}, \mathrm{Ba}$ and $\mathrm{Bb}$, appear to be highly conserved (Fig. 2) and deserve special comment. Firstly, those located in the $5^{\prime}$ part of the gene, up to position 947 (residue 315), encode the adenylate synthesis domain of the catalytic core (Schimmel, 1990). Interestingly, the class-defining motifs 1,2 and 3 of the alanyl-tRNA synthetases are encoded by regions $\mathrm{Aa}, \mathrm{Ab}$ and $\mathrm{Ad}$ respectively. Secondly, regions $\mathrm{Ba}$ and $\mathrm{Bb}$, positions 1691-1816 (residues 565-605) and positions 2015-2073 (residues 673-691), correspond neither to the catalytic core nor to the oligomerization domain defined by Schimmel (1990). The exact function of these protein regions remains controversial since (i) they are 'dispensable' in EcAlaS (Schimmel, 1990); (ii) they are missing in M. genitalium while A. thaliana lacks Bb; (iii) mutations G674D and G677D (Schimmel, 1990) located in region $\mathrm{Bb}$, affect the catalytic activity of EcAlaS. Thirdly, Schimmel et al. (1993) had proposed that tRNA synthetases are, like tRNA, organized into two major domains: the class-defining conserved domain containing the active site is needed for accepter-stem recognition while the non-conserved domain provides contact outside of this accepter stem with the distal parts of the tRNA molecule and, more precisely, the anticodon stem. Furthermore, it has recently been proposed that the region encompassing $\mathrm{Ba}$ and $\mathrm{Bb}$ may be needed specifically for synthetase-tRNA interactions involving parts of the tRNA structure outside of the accepter helix domain (Shiba et al., 1995). Such a strong conservation at the nucleotide sequence level in alaS genes from organisms from all kingdoms suggests that there were strong constraints during evolution on these parts of the genes, and strengthens the idea that tRNA synthetase genes derive from a common ancestor.

The same overall genetic organization of the $r e c A$ region exists in T. ferrooxidans and E. coli. In both cases, the recA-alaS intercistronic region contains an ORF, oraA in $E$. coli and recX in $T$. ferrooxidans, which could encode a polypeptide that aligns well with the putative RecX protein described by De Mot et al. (1994). Such a genetic linkage between the $r e c A, r e c X$ and alaS genes seems particular to $E$. coli and T. ferrooxidans. In fact, alaS but not recX is present in $R$. leguminosarum and Sin. meliloti (Selbitschka et al., 1991) while recA and $r e c X$ but not alaS are linked in Haem. influenzae (Fleischmann et al., 1995), and neither recX nor alaS has been found downstream of recA in Streptococcus pneumoniae (Martin et al., 1995), Synechococcus strain PCC 7002 (Murphy et al., 1990), M. genitalium (Fraser et al., 1995), Campylobacter jejuni (Guerry et al., 1994) and Helicobacter pylori (Schmitt et al., 1995). The genetic arrangement of the $\operatorname{rec} A, \operatorname{rec} \mathrm{X}$ and alaS genes is then the first reported case of identical genomic organization in T. ferrooxidans and E. coli of independently transcribed genes. Indeed, all genes which have so far been reported to display the same genetic organization belong to operonic structures i.e. ribosomal RNA operons (Venegas et al., 1988; Salazar et al., 1989), the cysDNC operon involved in sulfate assimilation (Fry \& Garcia, 1989), and the atpEFHAGDC operon encoding ATP synthase (Brown \& Rawlings, 1993; Brown et al., 1994). This indicates that the highly acidophilic, obligately chemolithotrophic $T$. ferrooxidans and the heterotrophic neutrophile $E$. coli, even though they belong to two different phylogenetic groups of the 'purple' bacteria and live in quite different biotopes are sufficiently related to share partly a common genomic organization. Also, in Vibrio cholerae, which belongs to the same subgroup of the purple bacteria as $E$. coli, the recX and alaS genes have been found 132 and $432 \mathrm{bp}$, respectively, downstream of $\operatorname{rec} A$. The AlaS sequence determined has a high degree of similarity to the other known alanyl-tRNA synthetases (N. Gupta, N. Bhasin \& A. Ghosh, personal communication).

\section{ACKNOWLEDGEMENTS}

The authors are indebted to Professor D. E. Rawlings for his gift of a pool of recombinant cosmids carrying the $T$. ferrooxidans genome and for helpful advice at the beginning of this work. We thank F. Nunzi from M. Bruschi's laboratory (BIP, IBSM, Marseille) for providing the rusticyanin antibody and the rusticyanin amino acid sequence prior to publication. We are grateful to Dr B. Bachmann for the alaS mutant. We gratefully acknowledge the Centre de Séquençage d'ADN de l'IBSM (Marseille). We thank Drs N. Gupta, N. Bhasin and A. 
Ghosh for sharing their unpublished observations. N.G. and A. B. acknowledge the support of Graduate Scholarships from l'Agence de l'Environnement et de la Maîtrise de l'Energie (ADEME). This work was supported by ADEME, le Bureau de Recherche Géologique et Minière (BRGM) and la Compagnie Générale des Matériaux (COGEMA).

\section{REFERENCES}

Aiba, H., Adhya, S. \& de Combrugghe, B. (1981). Evidence for two functional gal promoters in intact Escherichia coli cells. J Biol Chem 256, 11905-11910.

Altschul, S. F., Gish, W., Miller, W., Myers, E. W. \& Lipman, D. J. (1990). Basic local alignment search tool. J Mol Biol 215, 403-410.

Ausubel, F. M., Brent, R., Kingston, R. E., Moore, D. D., Seidman, J. G., Smith, J. A. \& Struhl, K. (1991). Current Protocols in Molecular Biology. New York: Wiley.

Blasco, F., lobbi, C., Giordano, G., Chippaux, M. \& Bonnefoy, V. (1989). Nitrate reductase of Escherichia coli: completion of the nucleotide sequence of the nar operon and reassessment of the role of the $\alpha$ and $\beta$ subunits in iron binding and electron transfer. Mol Gen Genet 218, 249-256.

Brown, L. D. \& Rawlings, D. E. (1993). A comparison of the structure of the $\mathrm{H}^{+}$-translocating ATP synthase from Thiobacillus ferrooxidans with those from other organisms. In Biobydrometallurgical Technologies, pp. 519-528. Edited by A. E. Torma, M. L. Apel \& C. L. Brierley. Warrendale, PA: Minerals, Metals and Materials Society.

Brown, L. D., Dennehy, M. E. \& Rawlings, D. E. (1994). The F1 genes of the $\mathrm{F}_{1} \mathrm{~F}_{0}$ ATP synthase from the acidophilic bacterium Thiobacillus ferrooxidans complement Escherichia coli $\mathrm{F}_{1}$ unc mutants. FEMS Microbiol Lett 122, 19-26.

Cairns-Smith, A. G., Hall, A. J. \& Russel, M. J. (1992). Mineral theories of the origin of life and an iron sulfide example. Origins Life Evol Biosphere 22, 161-180.

Chang, P. K. \& Dignam, J. D. (1990). Primary structure of alanyltRNA synthetase and the regulation of its mRNA level in Bombyx mori. J Biol Chem 265, 20898-20906.

Chun, C. T., Niemela, S. L. \& Miller, R. H. (1989). One step preparation of competent Escherichia coli. Transformation and storage of bacterial cells in the same solution. Proc Natl Acad Sci USA 86, 2172-2175.

Davis, M. W., Buechter, D. D. \& Schimmel, P. (1994). Functional dissection of a predicted class-defining motif in a class II tRNA synthetase of unknown structure. Biochemistry 33, 9904-9911.

De Mot, R., Schoofs, G. \& Vanderleyden, J. (1994). A putative regulatory gene downstream of recA is conserved in Gramnegative and Gram-positive bacteria. Nucleic Acids Res 7, 1313-1314.

Devereux, J., Haeberli, P. \& Smithies, O. (1984). A comprehensive set of sequence analysis programs for the VAX. Nucleic Acids Res 12, 387-395.

Eriani, G., Delarue, M., Poch, O., Gangloff, J. \& Moras, D. (1990). Partition of tRNA synthetases into two classes based on mutually exclusive sets of sequence motifs. Nature 347, 203-206.

Filley, S. J. \& Hill, K. A. W. (1993). Amino acid substitutions at position 73 in motif 2 of Escherichia coli alanyl-tRNA synthetase. Arch Biochem Biophys 307, 46-51.

Fleischmann, R. D., Adams, M. D., White, O. \& 37 other authors (1995). Whole-genome random sequencing and assembly of Haemophilus influenzae Rd. Science 269, 496-512.

Fraser, C. M., Gocayne, J. D., White, O. \& 26 other authors (1995).
The minimal gene complement of Mycoplasma genitalium. Science 270, 397-403.

Fry, I. J. \& Garcia, E. (1989). Cloning and characterization of Thiobacillus ferrooxidans genes involved in sulfur assimilation. In Biobydrometallurgy, pp. 172-185. Edited by J. Saley, R. G. L. McCready \& P. L. Wichlacz. Ottawa.

Guerry, P., Pope, P. M., Burr, D. H., Leifer, J., Joseph, S. W. \& Bourgeois, A. L. (1994). Development and characterization of recA mutants of Campylobacter jejuni for inclusion in attenuated vaccines. Infect Immun 62, 426-432.

Guiliani, N., Chippaux, M., Patte, J.-C. \& Bonnefoy, V. (1993). Perspectives in the genetics of Thiobacillus ferrooxidans. In Biohydrometallurgical Technologies, pp. 645-658. Edited by A. E. Torma, M. L. Apel \& C. L. Brierley. Warrendale, PA: Minerals, Metals and Materials Society.

Jasin, M., Regan, L. \& Schimmel, P. (1983). A modular arrangement of functional domains along the sequence of an aminoacyl tRNA synthetase. Nature 306, $441-447$.

Leduc, L. G. \& Ferroni, G. D. (1994). The chemolithotrophic bacterium Thiobacillus ferrooxidans. FEMS Microbiol Lett 108, 103-120.

Lu, Y. \& Hill, K. A. W. (1994). The invariant arginine in motif 2 of Escherichia coli alanyl tRNA synthetase is important for catalysis but not for substrate binding. J Biol Chem 269, 12137-12141.

Martin, B., Garcia, P., Castanié, M.-P. \& Claverys, J.-P. (1995). The recA gene of Streptococcus pneumoniae is part of a competenceinduced operon and controls lysogenic induction. Mol Microbiol 15, 367-379.

Miller, J. H. (1992). A Short Course in Bacterial Genetics: a Laboratory Manual and Handbook for Escherichia coli and Related Bacteria. Cold Spring Harbor, NY: Cold Spring Harbor Laboratory.

Miller, W. T. \& Schimmel, P. (1992). A retroviral-like metal binding motif in an aminoacyl-tRNA synthetase is important for tRNA recognition. Proc Natl Acad Sci USA 89, 2032-2035.

Miller, W. T., Hill, K. A. W. \& Schimmel, P. (1991). Evidence for a 'cysteine-histidine box' metal-binding site in an Escherichia coli aminoacyl-tRNA synthetase. Biochemistry 30, 6970-6976.

Murphy, R. C., Gasparich, G. E., Bryant, D. A. \& Porter, R. D. (1990). Nucleotide sequence and further characterization of the Synechococcus sp. strain PC7002 recA gene: complementation of a cyanobacterial recA mutation by the Escherichia coli recA gene. $J$ Bacteriol 172, 967-976.

Nagel, G. M. \& Doolittle, R. F. (1991). Evolution and relatedness in two aminoacyl-tRNA synthetase families. Proc Natl Acad Sci USA 88, 8121-8125.

Putney, S. D. \& Schimmel, P. (1981). An aminoacyl tRNA synthetase binds to a specific DNA sequence and regulates its gene transcription. Nature 291, 632-635.

Putney, S. D., Royal, N. J., De Vegvar, H. N., Herlihy, W. C., Biemann, K. \& Schimmel, P. (1981). Primary structure of a large aminoacyl-tRNA synthetase. Science 213, 1497-1501.

Ramesar, R. S., Woods, D. R. \& Rawlings, D. E. (1988). Cloning and expression in Escherichia coli of a recA-like gene from the acidophilic autotroph Thiobacillus ferrooxidans. J Gen Microbiol 134, 1141-1146.

Ramesar, R. S., Abratt, V., Woods, D. R. \& Rawlings, D. E. (1989). Nucleotide sequence and expression of a cloned Thiobacillus ferrooxidans recA gene in Escherichia coli. Gene 78, 1-8.

Ramirez, C., Schimmin, L. C., Leggatt, P. \& Matheson, A. T. (1994). Structure and transcription of the L11-L1-L10-L12 ribosomal 
protein gene operon from the extreme thermophilic archaeon Sulfolobus acidocaldarius. J Mol Biol 244, 242-249.

Rawlings, D. E., Woods, D. R. \& Mjoli, N. P. (1991). The cloning and structure of genes from the autotrophic biomining bacterium Thiobacillus ferrooxidans. Adv Gene Technol 2, 215-237.

Ribas de Pouplana, L., Buechter, D. D., Davis, M. W. \& Schimmel, P. (1993). Idiographic representation of conserved domain of a class II tRNA synthetase of unknown structure. Protein Sci 2, 2259-2262.

Ripmaster, T. L., Shiba, K. \& Schimmel, P. (1995). Wide crossspecies aminoacyl-tRNA synthetase replacement in vivo: yeast cytoplasmic alanine enzyme replaced by human polymyositis serum antigen. Proc Natl Acad Sci USA 92, 4932-4936.

Salazar, O., Takamiya, M. \& Orellana, O. (1989). Characterization of the two rRNA gene operons present in Thiobacillus ferrooxidans. FEBS Lett 176, 4409-4415.

Salles, C., Créancier, L., Claverys, J.-P. \& Méjean, V. (1992). The high level streptomycin resistance gene from Streptococcus pneumoniae is homologous to the ribosomal protein S12 gene of E. coli. Nucleic Acids Res 20, 6103.

Sambrook, J., Fritsch, E. F. \& Maniatis, T. (1989). Molecular Cloning: a Laboratory Manual, 2nd edn. Cold Spring Harbor, NY : Cold Spring Harbor Laboratory.

Sano, Y. (1993). Role of the recA-related gene adjacent to the recA gene in Pseudomonas aeruginosa. J Bacteriol 175, 2451-2454.

Schimmel, P. (1990). Alanine transfer RNA synthetase: structurefunction relationships and molecular recognition of transfer RNA. Adv Enzymol 63, 233-270.

Schimmel, P. (1991). Classes of aminoacyl-tRNA synthetases and the establishment of the genetic code. Trends Biochem Sci 16, 1-3.

Schimmel, P., Giegé, R., Moras, D. \& Yokohama, S. (1993). An operational RNA code for amino acids and possible relationship to genetic code. Proc Natl Acad Sci USA 90, 8763-8768.

Schmitt, W., Odenbreit, S., Heuermann, D. \& Haas, D. (1995).
Cloning of the Helicobacter pylori recA gene and functional characterization of its product. Mol Gen Genet 248, 563-572.

Selbitschka, W., Arnold, W., Priefer, U. B., Rottschafer, T., Schmidt, M., Simon, R. \& Puhler, A. (1991). Characterization of recA genes and recA mutants of Rhizobium meliloti and Rhizobium leguminosarum biovar viciae. Mol Gen Genet 229, 86-95.

Shi, J. P., Musier-Forsyth, K. \& Schimmel, P. (1994). Region of a conserved sequence motif in a class II tRNA synthetase needed for transfer of an activated amino acid to an RNA substrate. Biochemistry 33, 5312-5318.

Shiba, K., Ripmaster, T., Suzuki, N., Nichols, R., Plotz, P., Noda, T. \& Schimmel, P. (1995). Human alanyl-tRNA synthetase: conservation in evolution of catalytic core and microhelix recognition. Biochemistry 34, 10340-10349.

Temple, K. L. \& Colmer, A. R. (1951). The autotrophic oxidation of iron by a new bacterium: Thiobacillus ferrooxidans. J Bacteriol 62, 605-611.

Venegas, A., Hevia, E. \& Sanchez, H. (1988). Sequence of two tRNA genes from a Thiobacillus ferrooxidans ribosomal operon. Nucleic Acids Res 16, 8179.

Wilson, R., Ainscough, R., Anderson, K. \& 50 other authors (1994). $2.2 \mathrm{Mb}$ of contiguous nucleotide sequence from chromosome III of C. elegans. Nature 368, 32-38.

Wu, M.-X., Filley, S. J., Xiong, J., Lee, J. J. \& Hill, K. A. W. (1994). A cysteine in the C-terminal region of alanyl tRNA synthetase is important for aminoacylation activity. Biochemistry 33, 12260-12266.

Zaitsev, E., Alexseyev, A., Lanzov, V., Satin, L. \& Clark, A. J. (1994). Nucleotide sequence between $\operatorname{rec} A$ and alaSp in $E$. coli K12 and the sequence change in four recA mutations. Mutat Res $323,173-177$.

Received 13 January 1997; revised 18 March 1997; accepted 20 March 1997. 